\title{
ANALYSIS OF THE POSSIBILITY OF CALCULATING THE CHARGES ON THE EXAMPLE OF BRASSES
}

\begin{abstract}
This paper describes the subject of brasses and the method of their production from the secondary raw materials. It focuses on two very important aspects extremely important for today's world. The first of them is the theme of rational management of materials, particularly metallic scrap. The second issue is the growing importance of products made of brass, which in recent times get also special recognition in medicine. This article presents a proposal for a methodology for calculating the metal charge for brasses of two or more components. It turns out that by using suitable mathematical calculations one can accurately determine the amount of metal charge to obtain a product having the desired chemical composition and desired mechanical properties. Mathematical calculations are also presented in the graphical form for the visualization of dependency and a better explanation of the accepted approach.

Keywords: quality management castings, alloy, brass, calculating, batch
\end{abstract}

\section{Introduction}

Rational management of raw materials in the twenty-first century is not only an obligation arising from the shrinking amount of resources of metals from primary sources, but also the economy of the conducted process is much lower. According to the study [1] at the current consumption the estimated period of depletion of natural resources, without the use of secondary sources, is very short. While copper resources are determined for about 56 years, the resources of zinc are just 38 years and of tin 14 years. Therefore, the use of recycling in industrial production processes is a necessary process. In today's era copper alloys including brass are of increasing importance. They are widely used starting with domestic components to professional parts of the apparatus of research [2]. They are divided into forming brass and brass for the foundry. Given occurred realities it is necessary to use metals obtained in the way of recycling in the production of copper alloys. The composition of types of brass, depending on the purpose, is very diverse. However, its main and primary metals are just copper, and zinc. Other elements, in multicomponent brasses are negligible, which, however, can significantly affect the physicochemical and mechanical properties of the produced alloys.

The need for materials for the production coming from recycling creates a problem of determining the composition of raw material inputs in order to obtain a specific product at the output. Particularly problematic may be the need to make an alloy with the chemical composition quite different from materials held in the warehouse for remelting. In the literature you can find information on how to calculate the metal charge to obtain foundry pig iron, cast iron alloy, or production of silumins [3] of a determined composition. Meanwhile, research on copper alloys, including brass, bronze or lead mostly in the media about the chemical composition and supplied by an approved manufacturer [4]. It should also be noted that many studies take the subject brass strictly defined composition, but they do not indicate how to obtain the final material, especially copper alloys - brasses [5-7]. Especially when raw materials for its production are of quite different composition [8-12]. It should also be noted that a well-designed algorithm of the metal charge for brasses creates the possibility of writing a computer program, like the application to calculate the viscosity using the Iida models from the program Slag.

\section{Purpose and scope of the study}

The aim of the paper was to determine the optimal method of looking for the composition of the metal charge for a particular type of brass. Boundary conditions was the need to obtain the brass of well defined composition, as well as to apply to the charge only brass alloys belonging to different types, other than the type of brass which is a product of the melting process.

In order to calculate the burden, that is, the composition of the metal charge (the percentage of the individual components in the charge) it is necessary to determine the chemical composition

* $\quad$ STATE HIGHER VOCATIONAL SCHOOL IN GLOGÓW, GEOGÓW, POLSKA

** UNIVERSITY OF ZIELONA GÓRA, FACULTY OF MECHANICAL ENGINEERING, UL. PODGÓRNA 50, 65-246 ZIELONAGÓRA, POLSKA

*** INSTITUTE OF METALLURGY AND MATERIALS SCIENCE OF POLISH ACADEMY OF SCIENCES, UL. REYMONTA 25, 30-059 KRAKÓW, POLAND

**** BOLMET S.A., WIECHLICE 1, POLSKA

\# Corresponding author: 
of the charge in relation to a particular composition of the molten metal or the cast taking into account the changes in the components during smelting. The chemical composition of the finished product is usually standardized or dictated by the reception conditions. The calculation must take account of the relative melting loss of elements while melting. The presented calculations should also consider the relative melting loss dependent on the manner of smelting and material components. Knowing the value of the melting loss generated during smelting one can determine the average content of the element in the charge. The results of considerations presented below have been verified empirically in a metallurgical laboratory, where input materials were tested and output materials of specific samples of the alloy system.

The first case concerns the acquisition, as an output material, two-component brass of a strictly predetermined amount of zinc $\mathrm{Zn}$ in the system. In this case, the copper can be regarded as a solution being a solvent for the metallic zinc. Therefore, with the disposal of two other two-component brasses one can use the Eq. (1):

$$
\frac{B}{A}=\frac{Z n_{w}-Z n_{a}}{Z n_{b}-Z n_{w}}
$$

where:

$A, B$ - the content of the component $A$ and $B$ respectively,

$Z n_{w}$ - the content of the component in the charge,

$Z n_{a}$ - the content of the component in the material A,

$Z n_{b}$ - the content of the component in the material $B$.

According to the aforementioned relationship one can calculate the ratio of the two input materials into the system in order to obtain brass having the desired levels of zinc. Assuming that in the finished alloy we would like to get $2.49 \mathrm{wt} . \%$ zinc, while in the material $A$ its amount would be at the level of 1 wt. $\%$, and the material $B$ at 3 wt. $\%$, the ratio of the materials that should be used to compose such an alloy would be counted with use Eq. (2):

$$
\frac{B}{A}=\frac{Z n_{w}-Z n_{a}}{Z n_{b}-Z n_{w}}=\frac{2.49-1}{3-2.49}=\frac{1.49}{0.51}=2,92
$$

Hence the ratio of component $A$ to component $B$ is $1: 2.92$, or the content of component $A$ is $25.51 \mathrm{wt} . \%$, and $74.49 \mathrm{wt} . \%$ of component $B$. The result can be represented also in a diagrammatic manner (Fig. 1):

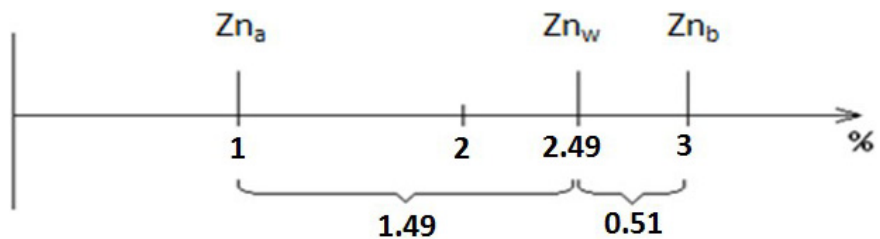

Fig. 1. Composition of brass charge $(A, B)$ to obtain brass of the composition $W$ - pre-determined amount of one element in brass

Continuing consideration for the adopted methodology it can be developed not only for two input materials, but also for any number of input materials that are two-component brasses.
Each system can in fact be lead to a two-component system, selecting, if necessary, two substrates, which yield one product with the theoretical composition, which, in the next step can be used for the calculation of the subsequent substrate to produce a product of desired composition. Furthermore, if for the starting material, the content of only one element (e.g. Zinc) were important, with no strict restrictions with regard to the content of other elements in the system output, in the case of the method shown multicomponent brass, i.e. with lead, special or highnickel could also be used.

The task becomes a little bit more complex in the case of the need to obtain brass with a precise amount of the two components in the starting material. First, let us analyse the two inputs, which are the charge for our system. When there are only two well-defined species of brass the task can be solved with a simple diagrammatic method. On the orthogonal coordinate system, the axis of ordinates (OY) is the content of the component $\mathrm{Zn}$ in brass, and the abscissa axis $(\mathrm{OX})$ is the content of the second component of brass, e.g. lead $\mathrm{Pb}$ (for leaded brass), $\mathrm{Sn}$ (for tin brass), Al (for aluminium brass), and so on. Between them is a distance that should be the point $\mathrm{W}$ corresponding to the coordinates ( $\mathrm{Znw}, \mathrm{Pbw}$ ) and therefore the co-ordinates of brass, which should be obtained. If it is present outside this segment, the available components will not allow to create brass of the specified amounts of the two elements. The distance between the segments AW (for component $B$ ) and BW (for component $A$ ) corresponds to the ratio of the amounts of ingredients in the burden of the charge, which allows the calculation of the percentage.

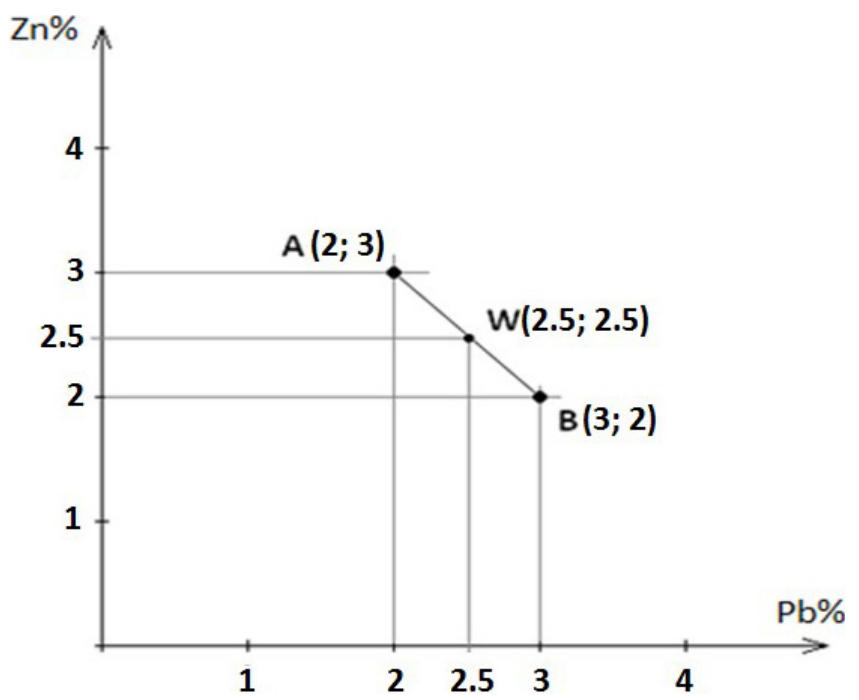

Fig. 2. Composition of brass charge $(A, B)$ to obtain brass of the composition $W$-pre-determined amount of two elements in brass.

The concept may be represented in Figure 2. In this example, the charge should be brass having the composition $A$ ( 2 wt.\% $\mathrm{Zn}$ and $3 \mathrm{wt} . \% \mathrm{~Pb}$ ), and $B$ (3 wt.\% $\mathrm{Zn}$ and 2 wt.\% $\mathrm{Pb}$ ), in order to obtain the starting material of the composition $W$. Making appropriate calculations the point in the desired composition can be determined, and also the amount of the burden of the component $A$ and $B$ to obtain the alloy shown. 
In order to solve the task in the arithmetical manner, an equation (3) of a line passing through two points should be determined: $A(2 ; 3), B(3 ; 2)$ :

$$
y=-x+5
$$

Then it must be checked if the point $W$ belongs to the line, substituting in place of the $y$ the desired amount of the $\mathrm{Zn}$ component, and in place of $x$ the desired amount of the $\mathrm{Pb}$ component. When the condition is fulfilled, you must calculate, with use the same Eq. (4), the distance between points $A(2 ; 3)$ and $W(2.5 ; 2.5)$ :

$$
d=\sqrt{\left(x_{2}-x_{1}\right)^{2}+\left(y_{2}-y_{1}\right)^{2}} \approx 0.7
$$

Similarly, the distance between points $\mathrm{B}(3 ; 2)$ and $\mathrm{W}(2.5,2.5)$ should be calculated, with use the same Eq. (4), which also is equal $\approx 0$. 7 .

The calculations carried out show that the ratio of component $A$ to $B$ for a particular composition should be $1: 1$, i.e. 50 wt. $\%$ of component $A$ and 50 wt.\% of component $B$.

Finally, in the calculation of the charge, which cannot be arranged with the two substrates the three input components can be used. Let us assume we want to obtain material of the content of 2.5 wt.\% $\mathrm{Zn}$ and $3 \mathrm{wt} . \% \mathrm{~Pb}$. As the substrate we want to use material $A$ having the composition ( $1 \mathrm{wt} . \% \mathrm{Zn}$, 1 wt.\% Pb), material $B$ having the composition (7 wt.\% $\mathrm{Zn}$, $1.5 \mathrm{wt} . \% \mathrm{~Pb}$ ), and material $C$ having the composition ( $2 \mathrm{wt} . \% \mathrm{Zn}$, $5 \mathrm{wt} . \% \mathrm{~Pb}$ ). As shown in the following Figure 3. Since the point " $\mathrm{W}$ " is inside the triangle specified with vertices indicating the composition of $A, B$ and $C$, it is possible to create such a product during the melting process. If this point was outside the triangle, it would not be impossible to create a material of the particular composition. In this situation, the content of components $A, B$ and $C$ are determined from the Eq. (5-7):

$$
\begin{aligned}
& B=\frac{b^{\prime} w}{b^{\prime} B} \cdot 100 \% \\
& A=\frac{a^{\prime} w}{a^{\prime} A} \cdot 100 \% \\
& C=\frac{c^{\prime} w}{c^{\prime} C} \cdot 100 \%
\end{aligned}
$$

As shown in the figure presented the solution with the use of a diagrammatic method is relatively intuitive. However, in case of arithmetic solution the calculations are slightly more complex than in the first case. At the beginning, of course, it should be determined whether or not the point " $w$ " is inside the triangle. For this purpose we set an Eq. (8) of the line passing through the points $A(1 ; 1)$ and $B(7 ; 1.5)$ :

$$
y=0.083 x+0.916
$$

Then the position of the point $C(2 ; 5)$ in relation to the line is checked in order to determine the shape of the triangle. After placing point $C$ to the equation it turns out that the $Y$

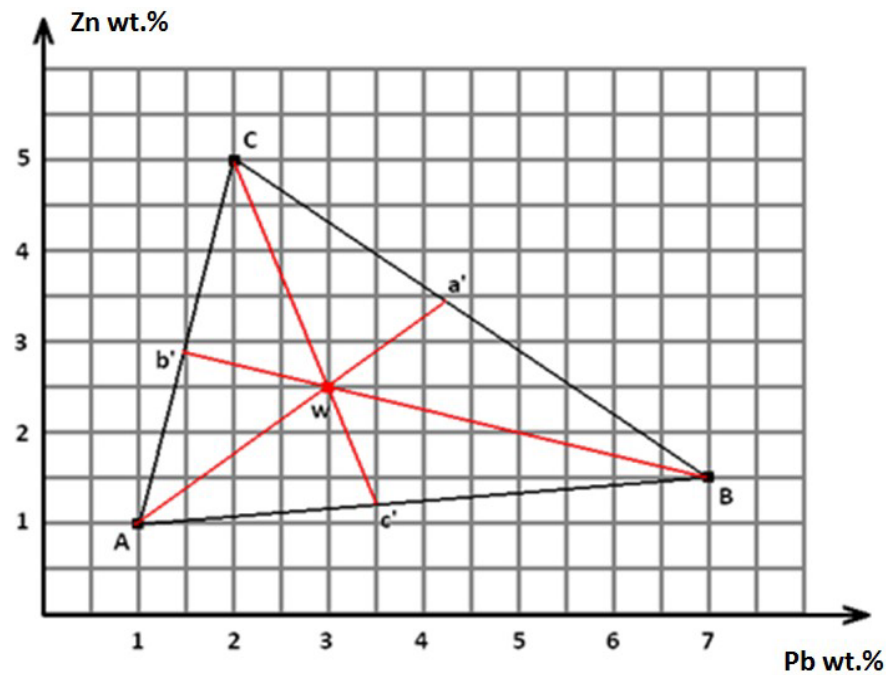

Fig. 3. Composition of brass charge $(A, B, C)$ to obtain brass of the composition $W$-pre-determined amount of two elements in brass

side is greater than the $X$ side, that is, the point $C$ lies over the straight line. The first area of the triangle will then circle the inequality (9):

$$
y \geq 0.083 x+0.916
$$

Similar calculations are performed for the other vertices of the triangle. The result are the 3 following inequalities (10):

$$
\left\{\begin{array}{c}
y \geq 0.083 x+0.916 \\
y \leq-0.7 x+6.4 \\
y \leq 4 x-3
\end{array}\right.
$$

Upon receipt of the system of equations, make sure that the set point $W$ is in the middle of the triangle, that is, whether substituting its data into the system of equations, they are met. To calculate the content of component $A$ according to the above formula the point $a^{\prime}$ should be designated. This is the point of intersection of the line Aw with the line BC. For this purpose, the line passing through points $\mathrm{A}(1,1)$ to $(3 ; 2.5)$ is determined, which gives the Eq. (11):

$$
y=0.75 x+0.25
$$

and then the position of a point $a^{\prime}$ is determined, according to the Eq. (12) and finally (13):

$$
\begin{aligned}
& \left\{\begin{array}{c}
y=0.75 x+0.25 \\
y=-0.7 x+6.4
\end{array}\right. \\
& x=4.24 ; y=3.43
\end{aligned}
$$

Then determine the length of a segment $a^{\prime}(4.24 ; 3.43)$ at $(3,2.5)$, according to the formula (1), which gives the value of $d=1.55$ and a length of the segment $a^{\prime}(4.24 ; 3.43) \mathrm{A}(1 ; 1)$ giving the value $d=4.05$. After putting the data into the formula (4), we obtain the amount of component $A$ to use: $3.82 \mathrm{wt} . \%$. Similar calculations are performed for component $B$ and $C$ getting the result: $B=2.75$ wt. $\%$ and $C=3.4$ wt. $\%$. 
This system can be fully resolved with the use of a diagrammatic method. In this case the segment "WW1" is formed consisting of ten (or one hundred) units. Then, in the segment from the point " $W$ " is put a half line No 1 upwards, inclined at any angle to the segment "WW1" (it may be also 90 degrees). Additionally, you should run a half line No 2 down from the point of "W1", which will be parallel to the half line No 1. On the half line No 1 segments of the lengths "a' $w$ " and "b' $w$ " are put, while on the half line No 2 are segments of the lengths "WA" and "WB". Finally, lines should be run: the first one passing through the points " $\mathrm{b}$ ' $\mathrm{B}$ " and one passing through the points "a'A". The first of the lines passing through the segment "WW1" determines the percentage of component $B$, and the second line crossing this segment will determine the percentage of component $A$ (Fig. 4).

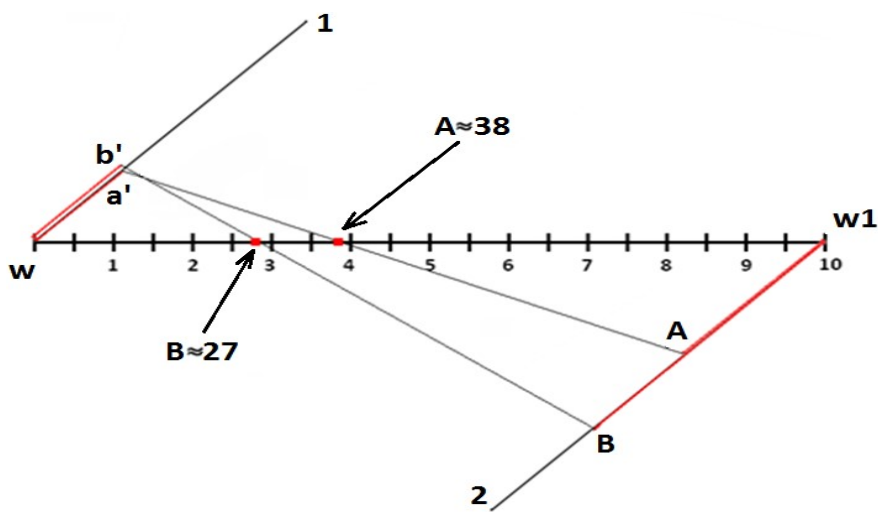

Fig. 4. Diagrammatic method for determining the amount of the charge (method 1)

The second way, using the diagrammatic method, allows in an equally simple way to determine the amount of material that must be used for loading. Here, too, segment "WW1" is formed consisting of ten (or one hundred) units. Then, at an angle of 90 degrees from the point of "W" line No 1 should be led upwards, but from the point of "W1" half line No 2 should be led down. Then on the half line No 1 the length of segment " $a$ ' $w$ ' should be put and on the half line No 2 the length of the segment "WA". Leading the line through the points "a" and " $\mathrm{A}$ " set aside on the half lines, causes intersection of segment "WW1" in the place determining the percentage of the amount of component $A$.

Then, at the intersection, by the line, the segment "WW1" lead down the half line No 3 . Now create a new segment of "W'W1",, which will be parallel to the segment "WW1" and it will combine the half line No 2 and No 3. This segment must be divided in the same scale as the segment "WW1". Then on the half line No 3, in the " $\mathrm{W}$ " " point, we put up the segment " $\mathrm{A}$ ' $\mathrm{C}$ " and on the half line No 2, from the point of "w1"”, we put down the segment "A'B". Leading the line passing through the points represented by the segments set aside for the half lines 3 and 2 , causes the intersection of the segment "W' $\mathrm{W} 1$ "' at the point "Y". The resulting segment " $W$ ' $Y$ " determines the percentage of component $B$, and the segment "YW1" determines the percentage of the amount of component $C$ (Fig. 5).

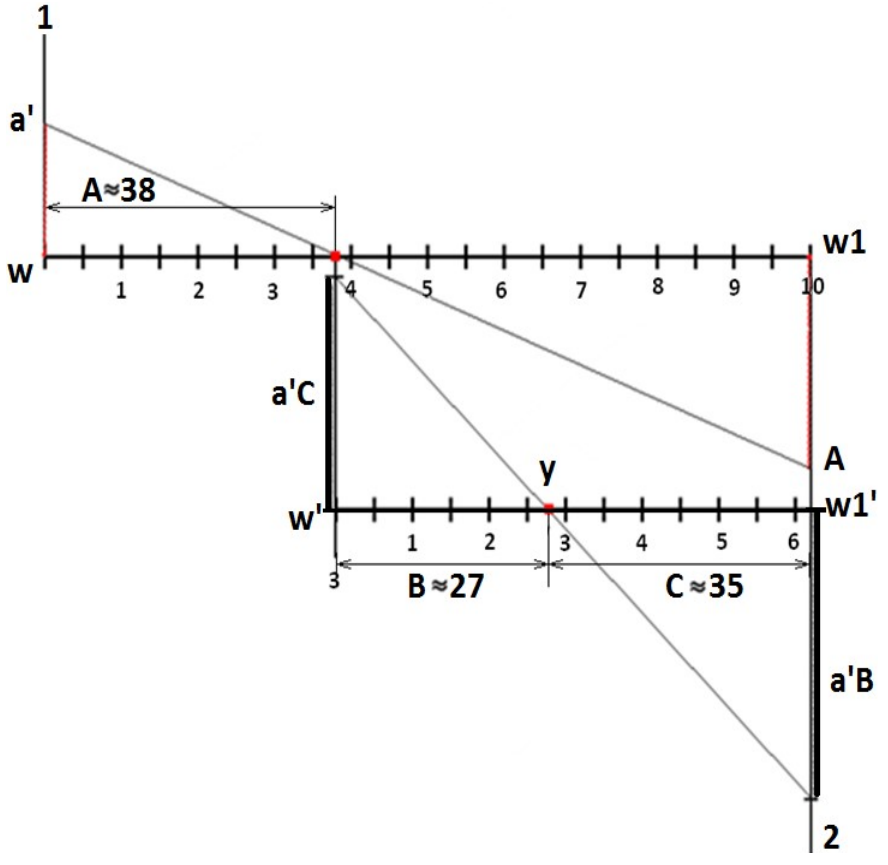

Fig. 5. Diagrammatic method for determining the amount of the charge (method 2)

\section{Results of tests}

In order to confirm the selected methodology appropriate laboratory tests had to be carried out. It was decided that the starting material should be lead brass having a composition of $\mathrm{Cu} 58$ wt.\%, Zn 40 wt.\% and $\mathrm{Pb} 2$ wt.\%. The raw materials for melting the starting product were Millberry copper, brass binary M62, two-component brass 63, post-production zinc sheet, zinc post-depreciation sheet and fatty lead scrap. The specified materials were melted in an induction laboratory furnace, in a graphite crucible, without the use of protective coverings. Analysis of the chemical composition of the samples is given in Table 1.

The three most important elements of lead brasses are copper, zinc and lead. The available materials the identified elements are present in the vast majority, the remaining elements are the traces.

On this basis, it can be concluded that the expected alloy can be prepared with such materials. It was decided to prepare 4 different melts with the ingot weight approx. $3 \mathrm{~kg}$. The first two melts were decided to be prepared with the 3 materials: Millberry copper, post-depreciation zinc sheet and lead scrap. The other two melts were decided to be prepared with the 4 different materials: two-component brass M62, two-component brass M63, postproduction zinc sheet and lead scrap. In the case of using 4 components, some preliminary assumptions had to be made, so that it was possible to apply the adopted methodology of calculation. Therefore, the 4-component system, has been transformed into a standard 3-component system, where the points corresponding to the two-component brasses were replaced with a single point corresponding to the average composition of the two materials comprising the alloy in a ratio of approximately 1:1. Assuming the established methodology burdens of the components were calculated, and they are presented in Table 2. 
TABLE 1

Elemental composition of raw materials in $\mathrm{wt} \%$

\begin{tabular}{|c|c|c|c|c|c|c|}
\hline & Millberry copper & $\begin{array}{c}\text { Two - component } \\
\text { brass M62 } \\
\end{array}$ & $\begin{array}{c}\text { Two - component } \\
\text { brass M63 } \\
\end{array}$ & $\begin{array}{c}\text { Post -production } \\
\text { zinc sheet }\end{array}$ & $\begin{array}{c}\text { Post - deprecia- } \\
\text { tion zinc sheet }\end{array}$ & Fatty lead scrap \\
\hline $\mathrm{Al}$ & & 0.001 & 0.001 & 0.006 & 0.058 & 0.001 \\
\hline As & 0.0005 & 0.002 & 0.001 & - & - & 0.002 \\
\hline $\mathrm{Bi}$ & 0.0005 & 0.002 & 0.001 & - & - & 0.02 \\
\hline $\mathrm{Cd}$ & - & - & - & 0.001 & 0.023 & 0.001 \\
\hline $\mathrm{Cu}$ & 99.99 & 61.91 & 63.51 & 0.182 & 0.103 & 0.027 \\
\hline $\mathrm{Fe}$ & 0.0006 & 0.004 & 0.002 & 0.001 & 0.003 & 0.006 \\
\hline $\mathrm{Ni}$ & 0.0005 & 0.005 & 0.001 & 0.004 & 0.003 & 0.001 \\
\hline $\mathrm{P}$ & 0.001 & 0.003 & 0.005 & - & - & 0.0002 \\
\hline $\mathrm{Pb}$ & 0.0005 & 0.219 & 0.004 & 0.003 & 0.69 & 99.44 \\
\hline $\mathrm{S}$ & 0.001 & - & - & - & - & 0.022 \\
\hline $\mathrm{Sb}$ & 0.001 & 0.002 & 0.002 & 0.005 & 0.002 & 0.456 \\
\hline $\mathrm{Sn}$ & 0.0005 & 0.065 & 0.002 & 0.018 & 0.298 & 0.002 \\
\hline $\mathrm{Te}$ & - & 0.001 & 0.001 & - & - & 0.002 \\
\hline $\mathrm{Zn}$ & 0.001 & 37.76 & 36.46 & 99.55 & 98.69 & 0.002 \\
\hline $\mathrm{Mn}$ & - & 0.016 & 0.002 & 0.001 & 0.001 & - \\
\hline $\mathrm{Mg}$ & - & - & - & 0.001 & 0.001 & - \\
\hline $\mathrm{Ti}$ & - & - & - & 0.22 & 0.119 & - \\
\hline $\mathrm{Cr}$ & - & - & - & 0.002 & 0.003 & - \\
\hline $\mathrm{Si}$ & - & 0.001 & 0.001 & - & - & - \\
\hline
\end{tabular}

TABLE 2

Amount of each component used in the melting process

\begin{tabular}{|c|c|c|c|c|c|c|c|c|c|c|c|c|}
\hline & \multicolumn{3}{|c|}{ Melt 1} & \multicolumn{3}{|c|}{ Melt 2} & \multicolumn{3}{|c|}{ Melt 3} & \multicolumn{3}{|c|}{ Melt 4} \\
\hline & \multicolumn{2}{|c|}{ Amount } & \multirow{2}{*}{$\begin{array}{c}\text { Correct. } \\
\text { [g] }\end{array}$} & \multicolumn{2}{|c|}{ Amount } & \multirow{2}{*}{$\begin{array}{c}\text { Correct. } \\
\text { [g] }\end{array}$} & \multicolumn{2}{|c|}{ Amount } & \multirow{2}{*}{$\begin{array}{c}\text { Correct. } \\
\text { [g] }\end{array}$} & \multicolumn{2}{|c|}{ Amount } & \multirow{2}{*}{$\begin{array}{c}\text { Correct. } \\
{[\mathrm{g}]} \\
\end{array}$} \\
\hline & [wt.\%] & [g] & & [ wt.\%] & [g] & & [ wt.\%] & [g] & & [ wt.\%] & [g] & \\
\hline Millberry copper & 57.7 & 1731 & 1741 & 57.7 & 1731 & 1739 & - & - & - & - & - & - \\
\hline $\begin{array}{l}\text { Two - component } \\
\text { brass M62 }\end{array}$ & - & - & - & - & - & - & 46.2 & 1386 & 1393 & 46.2 & 1386 & 1391 \\
\hline $\begin{array}{l}\text { Two - component } \\
\text { brass M63 }\end{array}$ & - & - & - & - & - & - & 46.2 & 1386 & 1392 & 46.2 & 1386 & 1380 \\
\hline $\begin{array}{c}\text { Post }- \text { production zinc } \\
\text { sheet }\end{array}$ & - & - & - & - & - & - & 5.7 & 171 & 167 & 5.7 & 171 & 164 \\
\hline $\begin{array}{l}\text { Post - depreciation } \\
\text { zinc sheet }\end{array}$ & 40.7 & 1221 & 1200 & 40.7 & 1221 & 1203 & - & - & - & - & - & - \\
\hline Lead scrap - fatty & 1.6 & 48 & 62 & 1.6 & 48 & 63 & 1.9 & 57 & 61 & 1.9 & 57 & 65 \\
\hline TOTAL & 100 & 3000 & 3003 & 100 & 3000 & 3005 & 100 & 3000 & 3013 & 100 & 3000 & 3000 \\
\hline
\end{tabular}

In relation to the calculated theoretical values some correction of the composition was made, related to the lossy in process of melting charge materials. Thus, when melting some part of the materials is oxidized and goes into slag. In accordance with the decrease in the thermodynamic potential already at $500 \mathrm{~K}$ the potential of the formation of copper oxides is approx. $-120 \mathrm{~kJ} / \mathrm{mol}$, lead oxides $-176 \mathrm{~kJ} / \mathrm{mol}$, and zinc oxides approx. $-300 \mathrm{~kJ} / \mathrm{mol}$. Of course, at higher temperatures these values are to grow in a positive direction, but their ratio remains unchanged. Thus, the highest chemical affinity for oxygen in the system is zinc, and the smallest copper and lead. Therefore, during the experiment carried out it was decided to increase the amount of copper to a small extent of not more than $0.3 \mathrm{wt} . \%$, however the amount of lead will increase by no more than $0.5 \mathrm{wt} . \%$. As regards the zinc, whose loss when conducting melt under the following conditions may be the biggest, it was decided to reduce the amount of the value not greater than $0.8 \mathrm{wt} . \%$, and its composition to complete at the final stage of melting maximally limiting its losses.

\section{Conclusions}

Based on the analyses, which have been supported by experimental studies it can be concluded that the proposed methodology for the calculation of two- or multi-component brass is correct. This gives greater possibilities for use of the input substrate materials of different compositions, similar to the starting material, in order to obtain an alloy with specific 
parameters and chemical composition. It is also worth noting that even in the absence of the possibility of creating a product with the desired composition, one can point to a product that can be obtained from the components held and which will be as close as possible to the chemical composition of the brass output. The presented analysis also gives additional possibilities which can be creating in the future a computer program to facilitate the implementation of the calculations presented above. A welldesigned computer application will be able, in a few seconds, to calculate the composition of brass, which are input to the desired composition, without making any tedious and time-consuming calculations. However, in the case of a lack of brass of the desired composition with the basic components of the input substrate it will also inform the user about it.

\section{Acknowledgements}

The support provided by the National Center for Research and Development under Project No. PBS3/A5/52/2015.

\section{REFERENCES}

[1] M. Kucharski, Recycling of non-ferrous metals (in Polish). Kraków, Wydaw. Akademii Górniczo-Hutniczej im. Stanisława Staszica (2010).

[2] M. Głowacka, Metallography (in Polish), Gdańsk Wydawnictwo Politechniki Gdańskiej (1996).

[3] J. Piątkowski, J. Szymszal, F. Binczyk, Calculation of bearing of metal batch with utilization of simplex algorithm (in Polish), Archives of Foundry Engineering 2 (6), 179-188 (2002), ISSN $1642-5308$
[4] F. Romankiewicz, M. Rybakowski, Modification of selected brass casting (in Polish). Solidification of Metals and Alloys 22, 118-123 (1995).

[5] S. Rzadkosz, M. Kranz, P. Nowicki, M. Piękoś, Refining processes of selected copper alloys, Archives of Foundry Engineering 9 (2), 29-34 (2009), ISSN (1897-3310).

[6] M. Kondracki, J. Szajnar, Possibilities for leaded brass replacement with multi-component brass, Archives of Foundry Engineering 7 (2), 57-64 (2007), ISSN (1897-3310).

[7] E. Ziółkowski, Theoretical basis of the parameters balance algorithm of the charge combined the charge materials with imprecise chemical constitution (in Polish), Archives of Foundry Engineering 19 (6), 443-448 (2006), ISSN 1642-5308.

[8] S. Biernat. A.W. Bydałek, Optimization of the brass melting, Archives of Foundry Engineering 14 (3), 5 (2014), 10.ISSN (1897-3310).

[9] A.W. Bydałek. A. Bydałek, The results of the brass refining process in the reducer conditions, Archives of Foundry Engineering 14 (1), 21-24 (2014), ISSN (1897-3310).

[10] A.W. Bydałek, H. Paul, K. Najman, D. Balcerek, K. Janas, Intermetalicphasis in the brass in the continous casting (in Polish), Archives of Foundry Engineering 6 (18), 251-256 (2006), ISSN 1642-5308.

[11] J. Kozana, S. Rzadkosz. M. Piękoś, Assessment of aluminium and silicon influence on strength properties and a microstructure of nickel brasses, Archives of Foundry Engineering 8 (4), 81-86 (2008), ISSN (1897-3310).

[12] W. Wołczyński, P. Kwapisiński, B. Kania, W. Wajda, W. Skuza, A.W. Bydałek, Numerical Model for Solidification Zones Selection in the Large Ingots, Archives of Foundry Engineering 15, 87-90 (2015). 